\title{
RESULTS AND EFFECTIVENESS OF ENVIRONMENTAL ASSESSMENT LEGAL MECHANISMS IN A CASE STUDY: URBAN PLANNING OF THE MUNICIPALITY OF VILLANUEVA DE CASTELLÓN (VALENCIA)
}

\author{
M. J. GOZALVO \\ Department of Urbanism, Universidad Politécnica de Valencia, Spain
}

\begin{abstract}
The increasing incidence of environmental policies has led to a profound adaptation of Spanish planning legislation, with the aim of integrating environmental constraints in urban planning decision-making. This study analyzes the results of the environmental assessment procedure in a recently elaborated planning document: the General Plan of the municipality of Villanueva de Castellón (Valencia). Our intention is to show, through the aforementioned practical example, how to combine and settle - in the urban planning - the different variables affecting the environment, as well as the documentation complexity that this entails. For this reason, the role and results of the various written documents is shown, items which in turn support the Environmental Sustainability Report. A determining sample of the effectiveness of the environmental assessment process has been the high-flood risk detection derived from the proximity of the Albaida river to populated areas. This circumstance has led to the modification of the initial proposed location of the main public park within the future planning to make it work as a protective element between the populated areas and the river.
\end{abstract}

Keywords: environmental policies, sustainable development, urban planning.

\section{INTRODUCTION}

This work focuses on the 'Environmental assessment', procedure that ensures that the environmental implications of decisions are taken into account before the decisions are made. For the 'Environmental Impact Assessment' (EIA) to be carried out, 'the developer may request the competent authority to say what should be covered by the EIA information to be provided by the developer (scoping stage); the developer must provide information on the environmental impact (EIA report - Annex IV); the environmental authorities and the public (and affected Member States) must be informed and consulted; the competent authority decides, taken into consideration the results of consultations. The public is informed of the decision afterwards and can challenge the decision before the courts' (European Commission, [1]).

There are few analyses - and therefore results published - of real urban planning cases. This is even clearer when dealing with small and medium-sized populations, despite the fact that they represent the highest percentage of municipalities in Spain. For this reason, we believe it is worth explaining through the specific case of a General Plan that is currently in process in the small-medium-sized Municipality of Villanueva de Castellon (in the province of Valencia) - the evolution of the 'Strategic Environmental Assessment' procedure which accompanies this planning document, highlighting the most significant aspects to illustrate the effectiveness of the legal tools at our disposal to achieve a sustainable 
114 Environmental and Economic Impact on Sustainable Development

development in terms of urban planning, and in turn, emphasize the problems caused by its implementation.

\section{2 'STRATEGIC ENVIRONMENTAL ASSESSMENT' PROCESSING PERIODS: CASE STUDY TIMELINE}

The Council of Villanueva de Castellon (7,400 inhabitants), has devoted the last few years to renovating its urban planning, like many other towns in the Valencian Community. The substantial change in Spanish planning legislation -and in the Valencian territory in particular - guided by the greater importance given to better environmental policies - as a result of the adoption of Law 9/2006, from 28 April, on the Assessment of the Effects of Certain Environment Plans and Programs (LEAE) - has meant that many municipalities have faced significant reorientation in terms of the urban planning they had already begun, even having to re-start the process in some cases. Villanueva de Castellon is one of many municipalities that have suffered this great processing overhaul.

In order to show the time cost involved in urban planning development and its application - adapted to the recent addition of the 'Strategic Environmental Assessment' - we here highlight the most important processing timeline milestones of the General Plan of Villanueva de Castellon [2]:

1. In May 2007, the council forwarded the General Plan's 'initial document' to the Generalitat Valenciana $(\mathrm{GV})$ to initiate its application within the regional Public Administration.

2. On 3 June 2010 (3 years later), the Environmental Agency of the GV replied to the council by issuing and handing the 'reference document', which specified the environmental criteria to be followed in the subsequent drafting phases of the document.

3. On 7 June 2011, after the municipal team drafted the 'Environmental Sustainability Report' following the guidelines established in the 'reference document', the Council agreed the opening date of the 45-day public bidding term, as well as the planning proposal supported by it.

4. In view of the suggestions and inquiries made by the interested public during the previously mentioned term - as well as the reports issued by the various government bodies involved - the Council produced the 'final version' or 'final planning proposal' along with all the corresponding specific studies, which were mostly environmental in nature.

5. As a result of the integration of environmental aspects - highlighted in the General Plan process - substantial changes were made to the initial planning proposal. The Council of Villanueva de Castellon, expanding on its public provision and broadcast, submitted the 'final planning proposal', which opened in December 2014 and lasted for a period of 45 days.

6. On 31 March 2015, the municipal Council approved the 'final planning proposal' and agreed to send it to the GV, urging for its final approval.

7. In May 2015, the GV officially received the final document of the 'General Plan'. The council is currently waiting for the GV environmental body to issue the "environmental report' and officially approve the document, which has not yet occurred.

The time periods mentioned above - meaning that the whole process now stretches to nine years - are undoubtedly not recommendable. Nevertheless, it is important to note that these delays are common in most municipalities trying to compose a new 'General Plan' following the entry into force of the LEAE assessment. 
The diversity of issues to be combined through the various specific environmental studies accompanying the main urban planning document - and the complexity of the administrative procedures that must be followed - grossly extend the processing times of these documents.

On the basis of the above, it is interesting to note that through a recent research study conducted on 31 municipalities in the region of La Safor (Valencia) [3], it is clear that none of the 11 new General Plans that started their application following the 'Strategic Environmental Assessment' have managed -thus far - to obtain the approval for this urban planning document, which is a matter of substantial importance for their respective municipalities.

\section{DOCUMENTARY COMPLEXITY, THROUGH THE DIVERSITY OF SPECIFIC STUDIES REQUIRED}

The necessary specific studies - alongside the planning documents - are shown in the following list, which gathers all the information required for the General Plan of the municipality of Villanueva de Castellón (Valencia) [2] that is the subject matter of this study:

1. Environmental Sustainability Report

2. Acoustic Study

3. Landscape Study

4. Study of Water Resource Adequacy

5. Inventory of Goods and Protected Areas

6. Mobility Study

7. Study of Tree Species

8. Flood-Risk Study

9. Economic Sustainability Report

There are also other specific studies that may be necessary, such as a 'Traffic and transport study', 'Housing demand study', etc. It is a well known fact among local urban planning professionals, that even though Valencian legislation (Ruling of 2006) only compels towns with a population of over 50,000 people to submit a 'Traffic and Transport study', in reality this procedure is being requested by Regional Administration in general, leading to towns of even as little as 600 inhabitants to commission them - together with their respective 'General Plans' - ignoring the fact that they have no traffic problems at all.

As specified by Gozalvo [3], 'our planning legislation is not adapted to the diversity of municipalities that make up our territory, an issue that becomes especially clear in smaller boroughs'. This lack of adaptation - we understand - is reflected also in the petition - by Regional Administration - of specific studies, when the size or planning arrangements of certain towns have not presented any particular problems.

The economic and temporal overload involved in the unnecessary development and processing of studies, can lead - especially in municipalities with low management capacity - to significant urban planning delays, meaning that existing and very important environmental impacts or risks remain neglected.

\section{LAND USE CONTROL, BY ESTABLISHING 'MAXIMUM OCCUPANCY RATES' IN THE URBAN PLAN}

The urban planning of the studied municipality follows the principles set by the Territorial Strategy of the Valencian Community (ETCV), which was recently adopted after being approved through a Regional Government Decree on 13 January 2011. 
116 Environmental and Economic Impact on Sustainable Development
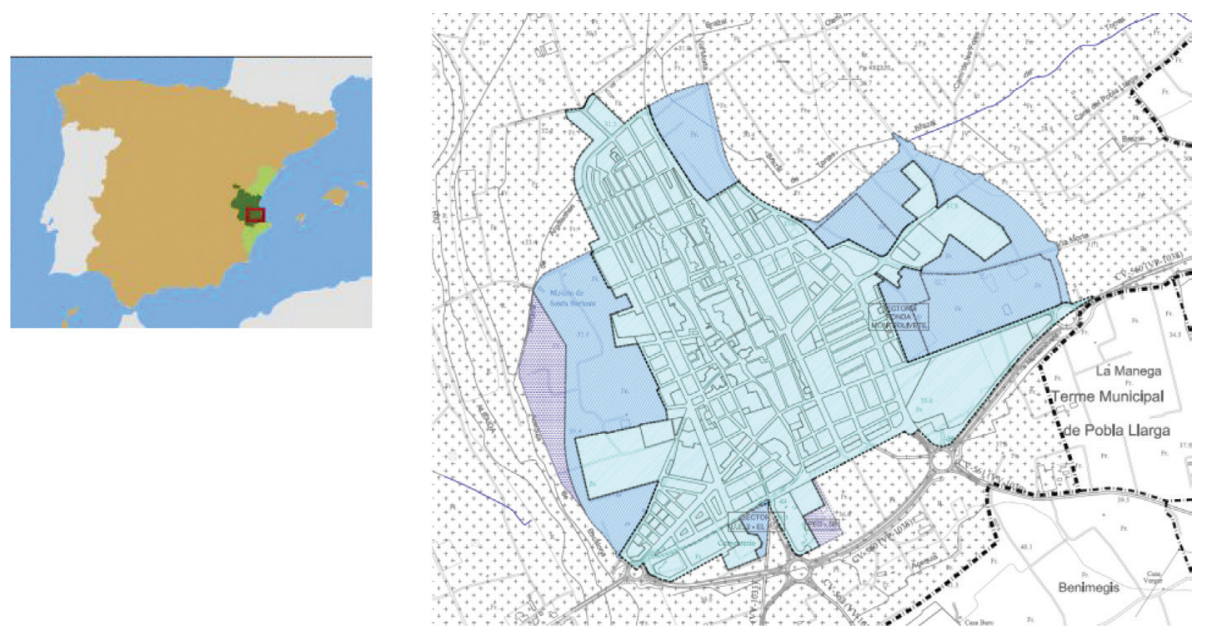

Figure 1: Situation of Villanueva de Castellon in Spain (left). Classification map of the new and still in process - Villanueva de Castellón 'General Plan' [2]. New urban growth areas around the nucleus of current population (right).

The ETCV guidelines establish - as a growth criterion for residential usage - the maintenance of our 'compact city' traditional model, which prioritizes the consolidation and extension of existing urban layouts, in order to define rational and sustainable land occupancy guidelines [4], as it is proven that this system involves a lower consumption of natural resources per unit area (Fig. 1).

Furthermore, the ETCV has set as its 23rd objective 'to define rational and sustainable land occupancy guidelines'. With this aim in mind, some planning criteria are established in order to determine ground occupancy rates, both for residential use and productive activities.

As a sample of the establishment of these rates, we here show some of the information for both residential use and economic activities - gathered in the studied General Plan of Villanueva de Castellon:

- Surface currently occupied by residential uses: $1,023,336 \mathrm{~m}^{2}$.

- Maximum rate of land occupancy for residential use: $31.88 \%$

- Maximum achievable surface for residential use: $1,349,576 \mathrm{~m}^{2}$.

- Surface currently occupied by economic activities: 794,104 $\mathrm{m}^{2}$.

- Maximum rate of land occupancy for economic activities: $21.70 \%$

- Maximum achievable surface for economic activities: $966,424.57 \mathrm{~m}^{2}$.

Thus, theoretical approaches find their practical enforcement in specific and binding resolutions, which are expressly calculated and set within the urban planning.

\section{TREATMENT GIVEN BY THE URBAN PLANNING TO THE MOST SIGNIFICANT ENVIRONMENTAL ASPECTS}

\subsection{The area degraded by an old quarry on the mound of 'El Castellet'}

Around 1990, the construction of a section of a major national highway (N-340) - on the border of the municipality of Villanueva de Castellon - resulted in a huge hollow pit 

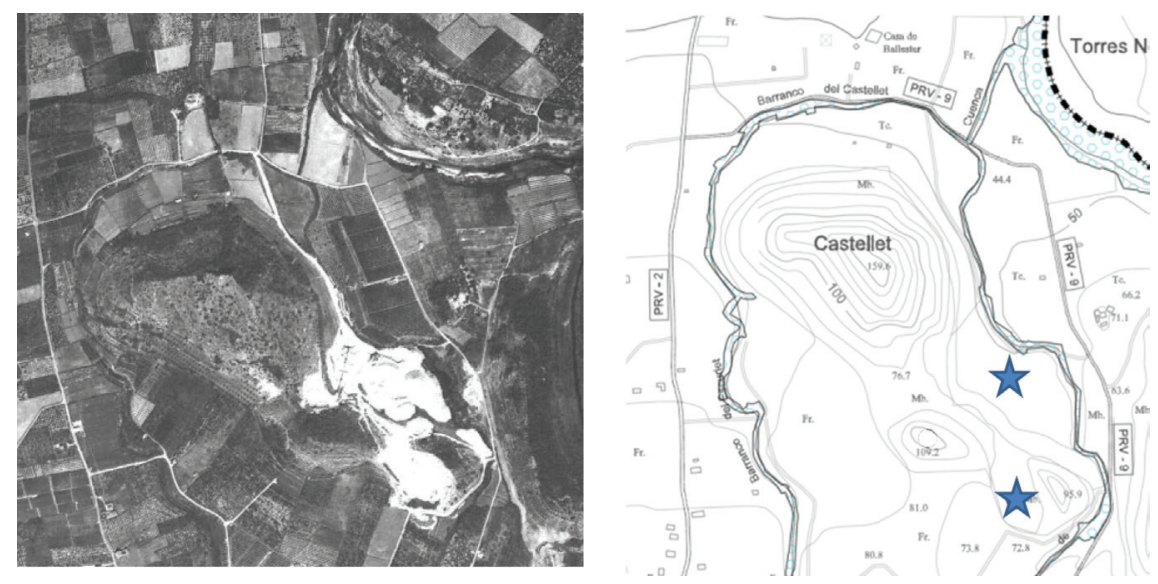

Figure 2: Mark left by the old quarry on the 'El Castellet' mound (left), where a 'regeneration area' is being proposed through creating a landfill for inert solid waste in the new 'General Plan' [2] (right).

$\left(171,622 \mathrm{~m}^{3}\right)$ on a mound of great scenic and cultural value for the local population. The reason is that this site - known as 'El Castellet' - was used as a dry earth quarry for the construction of the aforementioned highway. By the time people realized the harmful effects of this situation, the negative environmental impact had already become very evident, as seen in Fig. 2.

The solution proposed by the new municipal planning - for the morphological and environmental restoration of the mound - stems from the need to find an appropriate place for the deployment of an inert solid waste landfill, which happens to be a requirement whenever a new 'general master' is drafted, in accordance with the recommendations of the Integrated Waste Plan of the Valencian Community.

Therefore, a corrective measure - consisting of physically laying out an 'inert solid waste landfill', making use of the pit left in the mound's topography - is being proposed to offset the environmental impact caused by the old quarry.

Thus, the filling of - previously examined - inert solid waste, which usually comes from demolition work related to the construction sector, is expected to contribute to the morphological restoration of the mound's original volume. The subsequent replanting of the area - once the landfill is closed - will be the final operation in this attempt to recover the lost landscape of a large part of the 'El Castellet' mound.

The case exposed, exemplifies the first lesson learned in relation to the subject of this paper. Infrastructure construction in the years when the environmental assessment did not apply resulted in very negative impacts on the environment, which could have been avoided with proper advance planning, taking into account the effects on the environment, and had proposed appropriate corrective measures.

It is now, when through a new general plan of a municipality, planning try to correct past mistakes, with the 'Strategic Environmental Assessment'.

\subsection{Noise pollution}

The acoustic impact caused by urban development is analyzed through the elaboration of 'environmental noise studies' or 'municipal environmental noise plans', depending on 
118 Environmental and Economic Impact on Sustainable Development

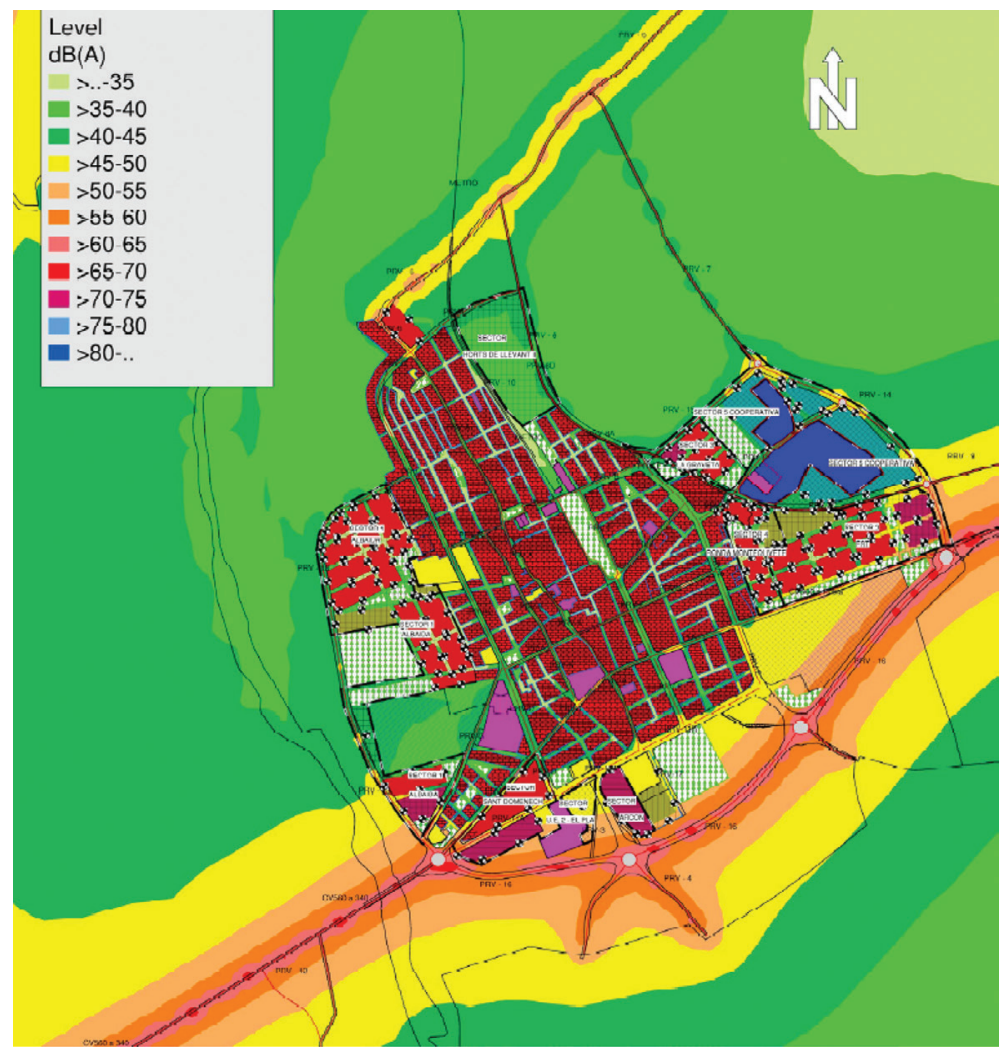

Figure 3: Layout detail of expected night noise levels once the planning is enforced, showing the sound belt $(>60 \mathrm{~dB}(\mathrm{~A}))$ produced by the ring road located in the southern edge of the town [5].

whether local populations exceed or fall below 20,000 inhabitants, in accordance with the provisions of the current environmental noise management and planning legislation of the Valencian Community.

The 'environmental noise study' produced - as a specific study of the 'General Plan' of Villanueva de Castellon - reveals the existence of areas that have been particularly affected by the infrastructure generated by urban development, which in our particular case is concentrated especially around a projected ring road, whose route runs around the southern part of town (Fig. 3).

For this reason, some corrective measures are being proposed to reduce noise impact, such as the use of special 'phono-absorbing' asphalt to pave the highway and the placement of acoustic panels next to it.

At the time of drafting the environmental noise study (2007), the cited ring road was not yet operational. Due to the delay in the General Plan's processing (which - as said before - is frequent in this type of urban planning documents because of their complexity and especially at present, given the constant legislative changes), the construction of this road went ahead before the adoption of the 'General Plan'. The road was officially opened in 2012.

Consequently, none of the corrective measures proposed by the General Plan to mitigate the environmental noise impact of the road were demanded during its construction, since the 
document that made these measures mandatory (the General Plan) is yet to be approved. On the other hand, the increase in costs meant that the application of such measures could not be assumed by the regional government responsible for building the road (Diputación de Valencia). Therefore, because the Council promoting the 'General Plan' is a different administration body, its implementation is being delayed even further, facing an uncertain future.

This case illustrates the importance of decision making from planning before construction, in particular, sufficiently in advance for proposed corrective measures can be put into practice.

5.3 The flood-risk analysis process and its influence - along with the landscape constraints - on the urban plan

The initial urban growth plan presented by the Council in question, takes into account floodrisk areas established by the regional government agency that is responsible for land management, through the first Territorial Flood Risk Action Plan of Valencia (PATRICOVA), which was approved in 2001 [6].

Hence, one of the areas of residential growth proposed in the 'General Plan', extends westward from the town, towards the riverbed of the nearby Albaida river, which explains why the area is called the 'Albaida Sector'. This area -according to PATRICOVA - initially presented no flooding risk (Fig. 4).

However, more detailed studies conducted by State agencies (CEDEX, 2002) [7] have highlighted the fact that this growth area is affected by flooding risk caused by the nearby river, and although the magnitude of the risk is low or moderate, it must be analyzed in depth to assess the possible continuance of the proposed residential growth area - the 'Albaida Sector' including - where appropriate - the necessary corrective measures.

For this reason, the regional administration claimed that the Council needed to issue a 'flooding risk study', which was produced by a specialized team from the Polytechnic University of Valencia (Fig. 5) [8].

The various results shown in the images can be explained by the fact that early studies (PATRICOVA and CEDEX) were regional studies and not detailed ones; also, they were
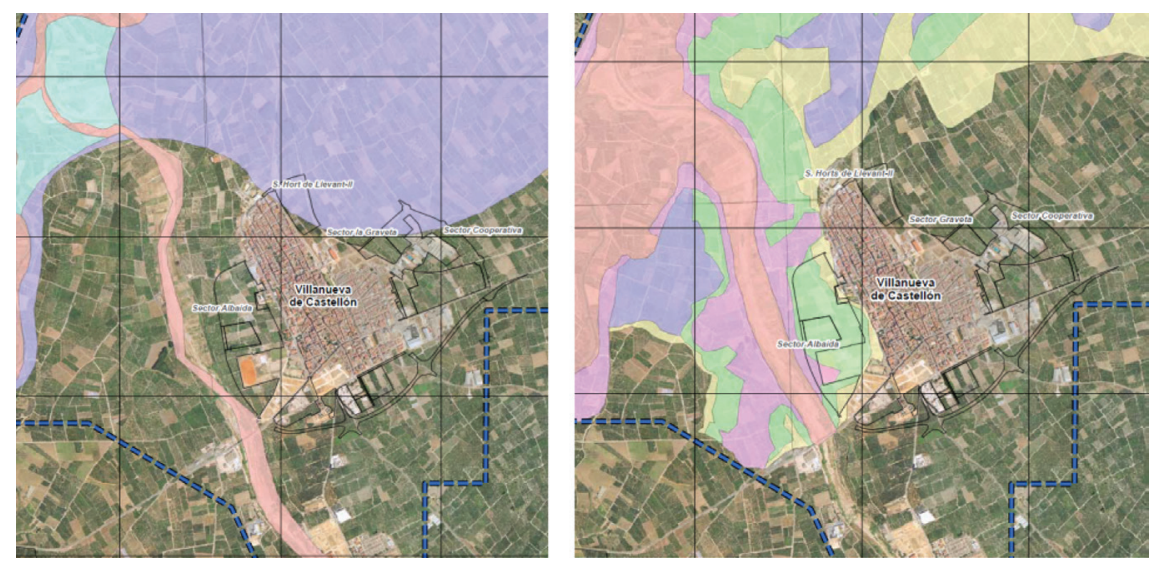

Figure 4: Flood-risk variation between the PATRICOVA (Regional Administration, 2001) affecting the northeastern part of the population (left) and CEDEX plan (State agency, 2002) affecting the west part of the population (right). 

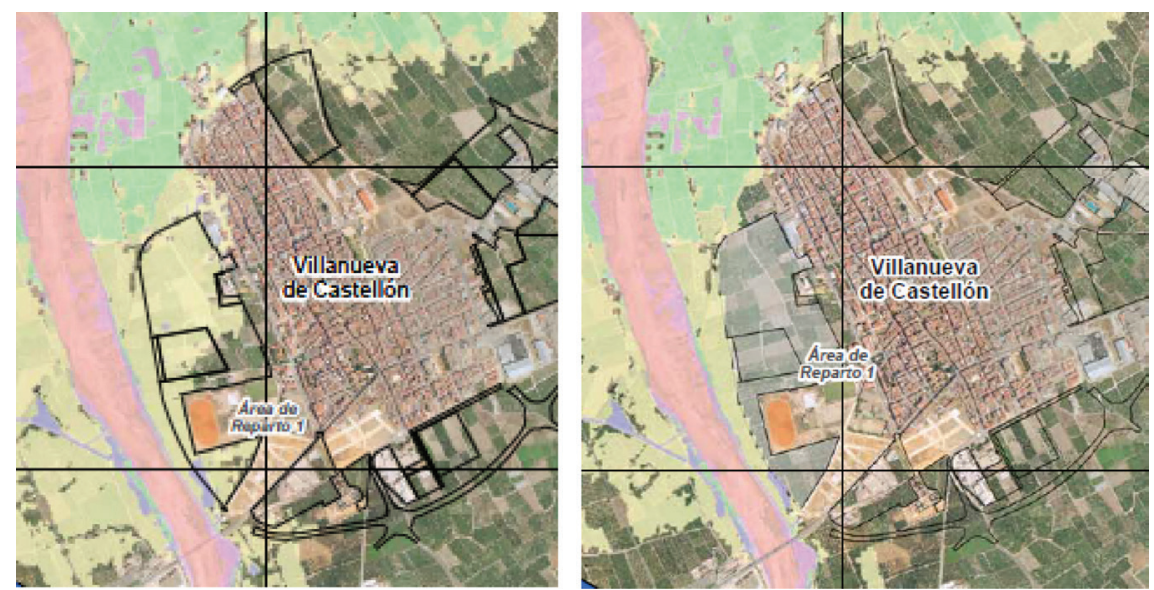

Figure 5: Flooding risk study issued by the Council and drafted by the Polytechnic University of Valencia [8]: 'Albaida Sector' flood risk in the current situation (left) and eliminated flood risk with corrective measures (right).

based on less accurate mapping and one-dimensional flow modelling. The flooding risk study issued by the Council and drafted by the Polytechnic University of Valencia used a more accurate modelling method, complemented by a two-dimensional flow analysis and focused on a more adequate study area. Also, the mapping conducted was more detailed and was based on the topographic lifting of the cross sections of the Albaida River, which produced more realistic results by taking into account the riverbed's real capacity.

However, during the consultation phase, which included sectoral supramunicipal administrations, an unfavorable report was issued by the supervising body of flooding risk studies. This report demanded the imposition of certain corrective and consistent measures regarding the 'Albaida Sector', including the elevation of the site on the side closest to the river - up to a certain height - to protect the area from water entry in case of a possible overflow of the Albaida river.

The aforementioned case highlights the importance of conducting adequate and detailed studies for each and every case, in order to analyze flooding risks properly.

At the same time, the regional government agency responsible for landscape management imposed a visual improvement constraint on the 'Albaida Sector' border, to ensure its proper landscape and visual integration with the river's surrounding area.

The response to both constraints (flooding and landscape) was carried out jointly by introducing appropriate modifications to the urban planning, as explained below.

\section{ASSESSMENT PROCESS CONCLUSIONS: INTEGRATION OF ENVIRONMENTAL ASPECTS INTO THE URBAN PLAN}

As a result of the 'Strategic Environmental Assessment' conducted in the Villanueva de Castellon 'General Plan' process, the final document contains several modifications to the draft version due to the integration and special attention paid to environmental aspects.

Nevertheless, the most crucial urban planning modification is that which arises from the joint consideration of both the landscape constraints and the corrective measures imposed due to flood risk (see Fig. 6). 

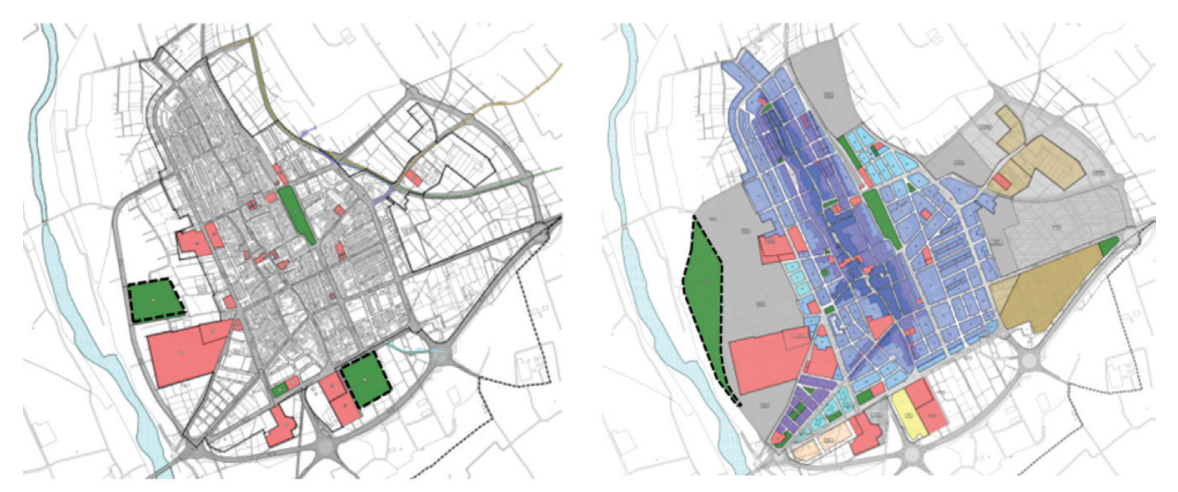

Figure 6: Urban plan in the initial version of the 'General Plan' - with two parks (left) - and in the final proposal with only one park (right).

The minimum total urban park area specified in the 'General Plan' in order to comply with urbanistic laws (and which was distributed in two large parks in the initial version: the first integrated within the 'Albaida Sector' and a second located to the South of the town) has been unified into one big park formed on the western edge of the 'Albaida Sector'.

This new park substantially changes the urban plan and serves two functions: it firstly sets up the town's Western facade towards the Albaida River, as an element that enables the integration of the urban landscape within the river's surroundings; at the same time, it visually softens the Albaida sector elevation - on its Western border - in response to the imposed flooding risk constraint.

The example above enables us to demonstrate the effectiveness of the 'Strategic Environmental Assessment' procedure in identifying risks that are inherent to urban development, integrating environmental aspects that have ultimately substantially modified the urban planning to provide appropriate solutions for them.

\section{FINAL CONCLUSIONS}

The procedure used to assess the effects of urban planning on the environment -through the 'Strategic Environmental Assessment', implemented relatively recently in Valencia - is very effective in detecting inherent urban development risks and adequately redirecting initial planning proposals.

However, the complex processing and diverse specific studies required for the development of planning documents - even though some of them are of questionable necessity to small municipalities - drives up costs and greatly complicates and slows their approval, making it extremely hard in some cases to draft a new municipal plan.

This situation often results in the delay of the entry into force of protective or corrective measures of environmental and cultural values contained in planning documents. Hence, it is possible that by the time these initiatives acquire legal status - once the planning is approved - it might be too late.

It is therefore essential to improve the 'Strategic Environmental Assessment' process, by simplifying the procedure itself and - especially - its practical application on the part of the Regional Administration.

In that sense, we believe that it would be worth conducting process optimization studies and also creating sectoral report and process promoting coordination bodies. 
122 Environmental and Economic Impact on Sustainable Development

Moreover, the last of the lessons learned is about the importance of properly managing flood risks. The urban planning's flooding risk analysis allows us to demonstrate the importance of investing in technology (and other means) to measure - as accurately and timely as possible - the magnitude of environmental risks and the effectiveness of corrective measures designed to amend them.

\section{REFERENCES}

[1] European Commission, available at http://ec.europa.eu/environment/eia/eia-legalcontext.htm

[2] Gozalvo, Maj., General Plan of the municipality of Villanueva de Castellón (Valencia), 2015. available at http://consultas.cma.gva.es/areas/medio_natural/evaluacion_ambiental/eae/planeamiento/2010.043.3.07/

[3] Gozalvo, M J., Green zones as a problem of urban management. Contribution from the study of 'structural green areas' in the province of Valencia. Special consideration to the municipalities of the La Safor region, (Doctoral Thesis), Department of Urbanism of Polytechnic University of Valencia, p. 597, 2015.

[4] Guidelines of the Territorial Strategy of the Valencian Community (ETCV). Generalitat Valenciana, pp. 65-70, 2011, available at www.citma.gva.es/estatico/areas/estrategia_ territorial $/ 30 / \mathrm{html} /$ index.html

[5] Molla, Fco, J. \& Poquet, R., EMIN Ingenieria Multidisciplinar. Environmental Noise Study of the 'General Plan' of Villanueva de Castellon (Valencia), 2009, available at http://consultas.cma.gva.es-/areas/medio_natural/evaluacion_ambiental/eae/planeamiento/2010.043.3.07/EstudisEspecifics/EstudiAcustic/

[6] TerritorialFloodRiskActionPlan of Valencia(PATRICOVA), which was approvedin 2001, available at http://cartoweb.cma.gva.es/visor/index.html?modo=web\&temas=Web_Ordenacion_Territorial\&capas=patricova

[7] Memory summary of flood risk mapping on the banks of river Jucar. Center for Studies and Experimentation of Public Works (CEDEX), Ministry of Development, Goverment of Spain, available at www.chj.es/es-es/ciudadano/participacion_publica/Documents/ Plan\%20Hidrol\%C3\%B3gico\%20de\%20cuenca/Cartografia_Riesgo_Inundacion_Ribera_Jucar.pdf

[8] Frances, F., Institute of Water \& Environmental Engineering of Polytechnic University of Valencia \& Hidrogaia S.L. Flooding Risk Study of the 'General Plan' of Villanueva de Castellon (Valencia), 2009, available at http://consultas.cma.gva.es/areas/medio_ natural/evaluacion_ambiental/eae/planeamiento/2010.043.3.07/EstudisEspecifics/Estudi\%20d'Inundabilitat/ 